\title{
The effect of sodium pentobarbital on attraction in the albino rat*
}

\author{
LEE A. BECKER, DENNIS C. WRIGHT, DAVID KELLEY, STEVE HARKINS \\ LAURA MAJCHER, and BRUCE LAMMERS \\ Lniversity of Missouri, Columbia. Missouri 65201
}

\begin{abstract}
Two "target" rats, one drugged and one undrugged, were tethered on opposite sides of an open arena in which single, undrugged "subject" rats were allowed to roam free. On the last 2 days of testing, the S rats spent significantly more time in physical contact with the undrugged target rat than with the drugged target rat. Prior adaptation to the arena of $S$ rats had no effect on the relative preferences for the target animals.
\end{abstract}

Latané and his colleagues have reported that several variables affect the gregariousness of the rat in an open field. They have defined gregariousness in terms of distance between animals and physical contact time and have demonstrated that gregariousness increases when rats are housed singly rather than in groups (Latané, Cappell, \& Joy, 1970; Latané, Schneider, Waring, \& Zweigenhaft, 1971), decreases when pairs of animals are sedated with chlorpromazine (Joy \& Latané, 1971) or alcohol (Cappell \& Latané, 1969), and increases when animal pairs are aroused by adrenalin (Joy \& Latané, 1971) or caffeine (Cappell \& Latané, 1969).

The rat is capable of making social discriminations. Mosley and Goodin (1972) demonstrated that differential contact preferences, within pairs of tethered target animals, could be operantly conditioned using food reinforcement, and Sharpe and Cooper (1966) demonstrated that avoidance of a specific rat could be conditioned by using either food or shock. There is little evidence of natural preference discriminations between conspecifics in the white rat. For example. cagemates are not preferred over strangers (Latané et al. 1971). Perhaps this is not surprising. Even the wild rat has a relatively undifferentiated dominance hierarchy (Barnett, 1963). and the laboratory rat shows little of the aggressive behaviors which apparently determine dominance hierarchies in the wild animal. Behaviors which lead to natural social discriminations may have been bred out of the white rat. Nevertheless, one of the recurring themes in Latané's work has been the hypothesis that rats "enjoy the opportunity for rewarding social interaction [Latané \& Werner. 1971, p. 148]." The present study tested this hypothesis in a social discrimination paradigm. Two target animals were twered on opposite sides of an open arena. The "responsiveness" of one of the tethered target animals

\footnotetext{
* Presented at the Midwestern Psychological Association meetings, Cleveland, May 1972. The study was supported in part by the Space Sciences Research Center, University of Missouri. and by a grant to L. A. B. from the University of Missouri Research Council.
}

was reduced by an injection of sodium pentobarbital. while the other received a placebo injection of saline. A nondrugged. free-roaming $S$ animal was then introduced into the arena, and his contact time with each of the target animals was recorded. The responsiveness hypothesis predicts that the placebo animal will be preferred to the unresponsive, noninteractive drugged animal.

This paradigm differs in some respects from that employed by Cappell and Latané (1969) and Joy and Latane (1971) to study drug effects on gregariousness in rats. Restricting drug administration to the tethered target animals reduces the confounding inherent in testing pairs of drugged. free-roaming animals. In the latter instance, drug-produced differences in contact time may be due to changes in the motor activity, attractiveness. andior motivation for social contast of either or both of the animals. The present paradigm is an analog of the "two-bottle preference" test commonly used to study motivated choice in rats, while the earlier paradigm more closely approximates the "one-bottle. acceptance" paradigm (Falk. 1972).

Prior adaptation to the arena should increase the relative preference for the placebo target animals. One of the most reliable findings of studies employing the circular arena is that contact scores increase and distance scores decrease across repeated trials (Latané, 1969: Latané \& Glass, 1968: Latané et al. 1971). It has been assumed that the arena is a novel stimulus which competes with the stimulation provided by another animal. As the arena is explored, it becomes familiar and attracts less of the rat's attention. The adapted animals should then pay more attention to the tethered target animals and make more reliable discriminations than do the nonadapted animals. The adapted animals should spend a greater percentage of contact time as well as total time in the arena in contact with the nondrugged target than do the nonadapted $\mathrm{S}$ animals.

\section{METHOD}

Subjects

The Ss were 16 male 90-day-old albino rats (Holtzman (co. 
Table 1

Total Contact Time and Percent of Total Time Spent in Contact with the Undrugged Target Animal Across Days

\begin{tabular}{|c|c|c|c|c|c|c|}
\hline \multirow[b]{2}{*}{ Index } & \multicolumn{6}{|c|}{ Days } \\
\hline & $1^{*}$ & $2^{*}$ & $3 \dagger$ & $4 \dagger$ & $5^{*}$ & $6^{*}$ \\
\hline Total contact time (seconds) & 135.3 & 146.1 & 169.2 & 157.5 & 166.9 & 150.8 \\
\hline $\begin{array}{l}\text { Percent of total contact time } \\
\text { spent with the undrugged animal }\end{array}$ & 59 & 52 & 48 & 53 & 66 & 65 \\
\hline
\end{tabular}

Madison, Wisconsin) housed individually with ad lib food and water. Two pairs of animals, $A B$ and $C D$, were randomly selected to act as targets. Half of the remaining 12 animals were assigned randomly as Ss for Target Pair AB and the other half as Ss for Target Pair CD.

\section{Apparatus}

Preferences were tested in a circular arena $4 \mathrm{ft}$ in diam (Latané, 1969). Pairs of target animals were tethered on opposite sides of the arena. Tethers were velcro collars which were placed just behind the forelegs. Attached to the collars were 10 -in. chains which were clipped to screw eyes placed about $6 \frac{1}{2}$ in. from the arena wall. These tethered target animals could freely move over about one-fifth of the floor area. Handswitchactivated counters and stopclocks and session timing were controlled with standard relay apparatus.

\section{Procedure}

\section{Adaptation}

Half of the Ss assigned to each target pair were randomly assigned to a preexposure condition (adapted). These adapted animals were each given 300 sec daily exposure to the arena for 12 days prior to testing. The remaining animals received no preexposure to the arena (nonadapted).

\section{Testing}

On Test Day 1, Target Animal A was given an IP injection of $15 \mathrm{mg} / \mathrm{kg}$ of sodium pentobarbital (Nembutal, Abbott). Target Animal B was injected with an equivalent volume $(1 \mathrm{cc} / \mathrm{kg})$ of $0.9 \%$ saline. Five minutes after injection, the target animals were tethered in the arena. The $S$ animal was placed in a bottomless startbox in the center of the arena. The box was removed, and the $S$ animal was allowed to roam free for $300 \mathrm{sec}$. The number of seconds that the $S$ animals spent in direct physical contact with each of the target animals was recorded, as were the number of squares crossed by each of the target animals. This last measure was used as a treatment check for the drug effect on general activity. Six animals were run with Target $P a i r A B$ and then six animals were run with $T$ arget $P$ air $C D$, with $C$ drugged (Nembutal) and D not drugged (saline). The order of testing was randomized within target pairs for each test day.

Similar procedures were followed on Day 2, except that the drug treatments were reversed (B and D, Nembutal; $A$ and $C$, saline) and $S s$ assigned to $T$ arget Pair $C D$ were tested before those assigned to Pair AB. Days 3 and 4 were nondrug control days on which all target animals received saline IP.

The procedures for drug injection and testing orders were changed for Days 5 and 6. On Day 5 the test order was: three Ss run with Target $A B$, three Ss run with $C D$, three with $A B$, and three with CD. Prior to running the second group of three Ss with a target pair, a booster injection of either $10 \mathrm{mg} / \mathrm{kg}$ of Nembutal or $0.66 \mathrm{cc} / \mathrm{kg}$ of saline was administered to each target animal. On Day 6, the testing sequence was reversed. Target Animals $B$ and $D$ were drugged on Day 5 and $A$ and $C$ were drugged on Day 6.

\section{RESULTS}

The effectiveness of the sodium pentobarbital treatment was checked by comparing the activity scores of the tethered target animals. These activity scores were analyzed in a $1 / 2$ fractional replication (Winer, 1962) of a 2 by 2 by 6 by 4 ANOVA. The factors were $S$ blocks (two random blocks), drug (sodium pentobarbital vs saline), trials (1-6), and days (Days 1, 2, 5, and 6). Drug, trials, and days were within-rat factors. Blocks and drug were confounded within days. The undrugged animals entered a larger number of areas $(M=32.9)$ than did the drugged animals $(\mathrm{M}=6.2)(\mathrm{F}=22.86, \mathrm{df}=1 / 2$, $\mathrm{p}<.05)$. There were no other significant effects. Control days (Days 3 and 4) activity scores for the tethered targets were analyzed in a Days by Trials ( 2 by 6) within-rat ANOVA. This analysis yielded no significant differences in activity scores. The mean number of areas entered on the control days (39.5) was about the same as for the undrugged animals during the treatment days. The treatment was considered effective.

A total contact time score for each $\mathrm{S}$ rat was computed by summing the time spent in contact with both target animals. These scores were analyzed in a 2 by 2 by 6 ANOVA with target pairs, adaptation, and days as the factors. This analysis yielded only a significant days effect $(F=3.07$, $d f=4 / 40, p<.05)$. Inspection of the daily means (shown in Table 1) indicates that the total contact time increased up to Day 3 and then fluctuated from Days 4-6. A Tukey (a) (Winer, 1962) a posteriori test of the days effect indicated that Days 2-6 were not significantly different from each other and that Day 1 had a significantly $(p<.05)$ lower mean total contact time $(M=135.3 \mathrm{sec})$ than Days $3(M=169.3 \mathrm{sec})$ and $5(M=166.9 \mathrm{sec})$.

Preference scores were expressed as the percent of total contact time that the free-roaming animal spent with the undrugged, tethered target animal. On the control days (Days 3 and 4), one of the target animals was randomly designated as the "undrugged" animal. Control day preferences were then expressed as the percent of total contact time spent with this randomly designated "undrugged" target. Preference scores were analyzed in a 2 by 2 by 6 ANOVA. The factors were target pairs ( $\mathrm{AB}$ and $\mathrm{CD}$ ), adaptation (prior adaptation vs no prior adaptation), and days (1-6). The only significant effect obtained was for days ( $F=4.06$, df $=$ $4 / 40, p<.01)$. Inspection of the daily means shown in 
Table 1 indicates that the percent preferences for the undrugged target rats were above $50 \%$ on each of the test days. A Tukey (a) a posteriori test of the daily means indicated that the mean preference for the undrugged target was greater $(p<.05)$ on Days 5 and 6 (66\% and $65 \%$, respectively) than on Days 2. 3. and 4 $(52 \%, 48 \%$, and $53 \%$. respectively). The mean preferonce un Day 1 (59\%) was not significantly different frum any of the other days.

The correlation between activity and contuit time juning the \& test dajs waj .51. This wrolution ads conputed un 96 ubscrvatior pairs, but 75 is 21 ? uverestilliciu of thic digrees of freedom because of the repeated measurements. With a more conservative estimate of $\mathrm{df}=47$, a correlation of .51 is significant at $p<.01$. This correlation included the effects of both drug treatment and preferences within treatments. When drug treatment was held constant, the correlations between activity and contact time were nonsignificant. Preferences for the drugged animals correlated $.26(\mathrm{df}=$ $47, p>.05$ ) with their activity rates, and for the undrugged animals the correlation was $.23(\mathrm{df}=47$, $p>.05)$. On the control days, the relationship between activity and contact times was $.14(\mathrm{df}=47, \mathrm{p}>.05)$.

\section{DISCUSSION}

On the last 2 days of testing, a sedated animal was less attractive than an undrugged animal. These findings extend previous research which indicated that the base rate of contact time for sedated animals was lower than for undrugged animals (Latané \& Glass, 1968) and that pairs of drugged animals interact with each other less than control pairs (Cappell \& Latane, 1969). Observation of the animals indicated that the drugged animal was not actively avoided. The drugged animal was attended to on the average of 1 min out of the total 5 -min period. The undrugged animal was attended to on the average of $1 \frac{1 / 2}{\mathrm{~min}}$. This drug-related behavior was correlated with the behavioral activity of the target animals and might therefore be viewed as supporting Latane's hypothesis that attraction in rats is mediated by mutual interaction.

It was also hypothesized that the relative preference for the undrugged target animal would be greater for adapted animals than for nonadapted animals. This prediction was not supported.

Reliable discriminations were obtained only on the last 2 days of testing. This result accompanied procedural changes which were made to counteract two effects seen during Days 1 and 2. First, the activity measure indicated that the drug effect wore off after about $30 \mathrm{~min}$. Since the testing phase for a given pair took about $40 \mathrm{~min}$, the target animal was recovering during the last one or two $\mathrm{S}$ animals. Second, it was noted that the activity of the undrugged target animal was much lower for the last testing trial than for the first. We attempted to overcome both of these effects by running each target pair with squads of three Ss and then administering a booster dose between squads. An internal comparison showed that the differences in ativity scores between the drugged and undrugged animali on Diys s and fo sombined $(D=36.7$ areas) was almost twice as great is in Days 1 and 2 combined $(D=$ 167 aresil. Howerer. the Days hy Drug Activity Score internction was not cignificunt $\mathrm{CF}=1.77$. $\mathrm{df}=3 / 6$. p>.05). It is unlikely that these changes in relative uctivity alone could decount for the increased

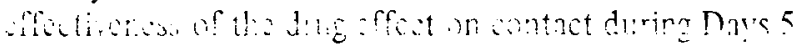

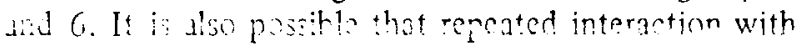
other animals, but not with the arena, makes the $S$ more sensitive to differences in the reactivity of other animals. Familiarity with that target's behaviors may have made the drug-nondrug distinction more salient for the Ss on Days 5 and 6 . If this were the case, adaptation to the arena with targets present would have produced more reliable target discriminations than did adaptation to the arena alone.

Finally, it should be recalled that the correlations between activity and contact times were not significant when drug conditions were held constant. This suggests that activity may not be a reliable indicator of "responsiveness," except when comparing extreme behavioral conditions such as drugged and undrugged animals. It may also indicate that neither responsiveness nor activity was the primary factor influencing contact times in this study. Nembutal could undoubtedly alter a number of factors that influence gregariousness. For example, the drugged animal probably smells strange to another animal, and given the known effects of barbiturates, the semianesthetized animal is as cold thermally as he is socially.

\section{REFERENCES}

Barnett, S. A. The rat: A study of behaviour. London: Methuen, 1963.

Cappell, H., \& Latané, B. Effects of alcohol and caffeine on the social and emotional behavior of the rat. Quarterly Journal of Studies on Alcohol, 1969, 30, 345-346.

Falk, J. L. Determining changes in vital functions: Ingestion. In R. D. Myers (Ed.), Methods in psychology. New York: Academic Press, 1971. Pp. 301-331.

Joy, V.. \& Latane. B. Autonomic arousal and affiliation in rats. Psychonomic Science, 1971, 25, 299-300.

Latané, B. Gregariousness and fear in laboratory rats. Journal of Experimental Social Psychology, 1969, 5, 61-69.

Latané, B., Cappell, H., \& Joy, V. Social deprivation, housing density, and gregariousness in rats. Journal of Comparative \& Physiological Psychology, 1970, 70, 221-227.

Latané, B., \& Glass, D. C. Social and nonsocial attraction in rats. Journal of Personality \& Social Psychology, 1968, 9. 142-146.

Latané, B., Schneider, E., Waring, P., \& Zweigenhaft, R. The specificity of social attraction in rats. Psychonomic Science, 1971, 23, 28-29.

Latané, B., \& Werner. C. Social and non-social sources of attraction in rats. Psychonomic Science, 1971, 24, 147-148.

Mosley, D., \& Goodin, L. Operant conditioning of social preference in Rattus nor'egicus albinicus. Paper presented at the Psi Chi session of the almulal meeting of the Midwestern Psychological Association. Cleveland. May 1972. 
Sharpe, L. G., \& Cooper, J. B. Interindividual recognition in albino rats. Journal of Genetic Psychology, 1966, 109, 151-161.

Winer, B. J. Stotistical principles in experimental design. New
York: McGraw-Hill, 1962.

(Received for publication August 3, 1972;

revision received November 20,1972 .) 